\title{
Opinion
}

\section{Conception of a Fertile Mindset}

\author{
Connie Stark, RNC, CPC* \\ ART of Wellness Certified Nurse Specialist and Fertility Consultant, Chicago, Illinois, USA \\ *Corresponding authors \\ Connie Stark, RNC, CPC \\ Founder and President of ART of Wellness, ART of Wellness Certified Nurse Specialist and Fertility Consultant, Chicago, Illinois, USA; \\ E-mail: artofwellnesscoach@gmail.com
}

\section{Article information}

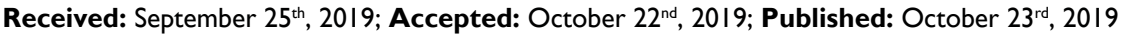

Cite this article

Stark C. Conception of a fertile mindset. Women Health Open J. 2019; 5(I): 16-18. doi: 10.17140/WHOJ-5-I32

A single thought creates an emotion, just as a single egg and A sperm create an embryo. When it comes to create a family through the fertility treatments, having a healthy and positive mindset make the difference in positive outcomes.

Preconception care is increasingly being incorporated into position statements or guidelines worldwide. ${ }^{1-4}$

Our brains are triggered by a thought that creates array of emotions or feelings. When a feeling is experienced, it's within the moment of a single thought that sends a signal to the brain to create a particular emotion.

Let's review some definitions to wrap our brains around the importance of how mindset can make a difference.

Dictionary.com ${ }^{5}$ defines:

- Emotion as an effective state of consciousness in which joy, sorrow, fear, hate, or the like, is experienced, as distinguished from cognitive and volitional states of consciousness.

- Infertility as: 1. Not fertility, unproductive, sterile, barren; 2. Not productive.

- Fertility as: 1 . The ability to produce offspring; 2 . The state or quality of being fertile.

When people visit fertility centers, they are already experiencing emotions beyond their control. Most likely, they lean toward negative mindset. It's understandable as hearing the word "infertility" triggers the thought of "I'll never have a baby" thereby creating the emotion of sadness for anyone who wants to be a parent.
On the other hand, when people say the word "Fertility", it creates a positive thought of being in a fertile state and having the power to reproduce. Emotions of happiness exude from anyone who wants to be a parent.

If a single word creates a thought that equals an emotion, which triggers a ripple effect of emotion and the behaviors resulting from emotions, then "Why" do we or should we focus on the word "Infertility" when trying to get pregnant?

This single word "fertility" or "fertile" will set your emotions and internal dialogue to a positive mindset. When you have a "Positive" mindset, it leads you to feel empowered through your fertility journey and to know that each lifestyle choice you make will enhance good decisions, healthy choices and positive emotional outcomes as you pursue the exciting path to parenthood.

Dr. Domar established the first Mind/Body Center for Women's Health, as well as the first Mind/Body Program for Fertility agrees and teaches taking back control of your life, cope with infertility in a much more positive way, and learn about lifestyle habits that can enhance your fertility and contribute to your happiness and good health for the rest of your life.,7

Let's discuss $3 \frac{1}{2}$ immediate mindset choices to live IN fertility:

\section{Plan for Your Fertility Treatment to Work}

When you make a decision to start a treatment cycle at the start of your period, Think and reframe your thought from "of course I'm not pregnant, I knew I wouldn't get pregnant to I will continue to prepare for pregnancy this month the start of my period is the beginning".

A lot of emotional, financial, physical and social effort goes into each cycle, plan for it to work. Change the focus. Re- 
member the power of the mindset and thoughts.

\section{Find Your Purpose: Be Your Best Self!}

Your diagnosis is a label. Names a body function, not You. It does not define who you are so why live your diagnosis? This is a temporary life crisis; your bigger better self is stronger and alive, find it again. Think about what defined you prior to this current life stage of reproduction? Ignite your hobbies, talents, relationships again. You will find your spirit which will strengthen your thoughts throughout your present moment of treatment and outcome. You are not your diagnosis, live life without that limitation. I was given a diagnosis 30 years ago, due to my severe nerve disease in my right leg, it was unknown if I would be able to walk without support of my wheelchair, crutches or cane and my unknown if I would be able to carry a pregnancy. Honestly, as I first went with it, I remember my thoughts were my diagnosis, which kept me exactly where my mindset was which created the emotions to stay limited. I had a breaking point to make a choice between to walk or not to walk. The two choices had 2 very different mindsets and ways to live. I chose to walk. And from that point, each of my decisions of treatments, therapies and so much more had to follow my vision. Well, I am now 15 years out of a wheelchair with no walking assistance and have 3 beautiful adult children in my life. Believe me this was not the easiest way but my vision was to walk. See your vision choose that mindset that leads and prepares you to that life. It will constantly change and evolve, but I promise all good will come even through your dark moments. It may look different and feel different but the movement from month to month will prepare you for the path that will lead you to parenthood. I am not promising you your mindset shift will get you pregnant but what I will promise you that it makes a positive difference for the rest of your life. Once you choose your path for the month, stay with it, your positive mindset is your greatest tool. Don't be fooled to think a positive mindset is always about happiness and smiles. It's about blood sweat and tears, the daily practice and diligence to your vision is what will keep your focus clear to your vision.

\section{Gratitude: Being Thankful for Your Life's Moments}

Create a ritual every day to spend time to journal 3 things you are thankful for. Buy yourself a journal book. Write and keep writing, no rules except a minimum of 3 things, even if you write the same 3 things.

Example: "I am thankful that I have insurance to pay for my intrauterine insemination (IUI)." on time."

"I am thankful I got a 7 am appointment today so I can get to work.

"I am thankful my girlfriend asks me to go to dinner tonight, I love ber company."

It resets your mindset!! Put affirmations on your mirror or anywhere in your house, car, office with pos it's to remind you to Be Your Best Self and your worth it you are more than your diagnosis.

According to Georgia Witkin, $\mathrm{PhD}$, author of The Chronicles of Infertility states, "You may not have control over the physical effects of fertility treatment, but you can take control over many of the psychological effects. What you think and what you do shapes what you feel, so choose thoughts and behaviors that reinforce your sense of control. Work and play will help you cope with this journey, so don't wait until you are overwhelmed. Make your mental health a priority now". ${ }^{8}$

And now the $1 / 2$ : Allow time in your day to be sad, mad or any emotion you have. Make an appointment with yourself that you can sit in silence to just be. Being aware of your thoughts without judgment. Acknowledge them and let them pass.

These $3 \frac{1}{2}$ action steps are just the beginning to embrace and allow the MINDSET to live

\section{YOUR BEST FERTIE SELF}

Choose present moments and check-in with yourself to make sure your thoughts are not creating emotions of sadness from your past or predicting your unknown future. It's in the present mindset that needs to be strong and practiced.

Honor your story and this stage of your life by learning a new mindset and start your living

\section{YOUR BEST SELF}

One of my favorite quotes written by Dr. Wayne Dyer states:

"If you change the way you look at things, the things you look at change".

It's your choice you have the power and control. Will you choose conception with a fertile mindset?

\section{REFERENCES}

1. Shawe J, Delbaere I, Ekstrand M, et al. Preconception care policy, guidelines, recommendations and services across six, European countries: Belgium (Flanders), Denmark, Italy, the Netherlands, Sweden and the United Kingdom. Eur J Contracept Reprod Health Care. 2015; 20: 77-87. doi: 10.3109/13625187.2014.990088

2. Jack BW, Atrash H, Coonrod DV, Moos MK, O’Donnell J, Johnson $\mathrm{K}$. The clinical content of preconception care: An overview and preparation of this supplement. Am J Obstet Gynecol. 2008; 199: S266-S279. doi: 10.1016/j.ajog.2008.07.067

3. National Institute for Health and Clinical Excellence (NICE). Dietary Interventions and Physical Activity Interventions for Weight Management before, During and after Pregnancy. London, UK: RCOG Press; 2010. 
ber 24, 2019.

4. National Institute for Health and Clinical Excellence (NICE).
Fertility: Assessment and Treatment for People with Fertility Problems. London, UK: RCOG Press; 2012.

5. Word of the Day. https://www.dictionary.com/. Accessed September 24, 2019.

6. Domar AD. Domar Center: For Mind/Body Health. Web site. https://www.domarcenter.com/mind-body/. Accessed Septem-
7. Rooney KL, Domar AD. The relation between stress nad infertility. Dialogues Clin Neurosci. 2018; 20(1): 41-47.

8. Witkin G. The Chronicles of Infertility. Web site. https://www. psychologytoday.com/intl/blog/the-chronicles-infertility. Accessed September 24, 2019. 